\title{
Blue Ocean Shift: Evidence-Based Practice in the Professional Development of Teachers
}

\author{
https://doi.org/10.3991/ijac.v12i2.10688 \\ Jenna Nelson ${ }^{(凶)}$ \\ Concordia University Chicago, Illinois, USA \\ jenna.nelson@cuchicago.edu \\ Hank Bohanon \\ Loyola University Chicago, Chicago, USA
}

\begin{abstract}
With the implementation of Every Student Succeeds Act (ESSA) in the United States, teachers have been given new responsibilities tied to supporting student scholastic and behavioral needs. The recent implementation of ESSA has left educators with minimal professional development support options to acquire skills to support students under this Act. To meet the diverse professional needs of teachers, it is necessary to look toward new cost-effective methods for professional development that stretch beyond in-person trainings, and that will prepare teachers to support the scholastic and behavioral needs of all learners. The authors propose incorporating the Blue Ocean Shift (BOS) strategy to identify alternative methods for teacher development. BOS comes from the business setting and is a strategy used in market development. The authors apply BOS to education through exposing its applicability as an assessment process. This assessment process can support the identification and development of online teaching tools for supporting multi-tiered systems of supports (MTSS) coaches in their training of teachers for school improvement efforts. The authors analyze the current professional development options provided to teachers and evaluate the use of BOS to determine innovative practices that MTSS coaches can implement to develop teacher skills and promote student learning.
\end{abstract}

Keywords-Blue Ocean Shift; teacher professional development; online professional development; multi-tiered systems of supports (MTSS)

\section{Introduction}

Despite increased demand for skill improvement for educators, there are few alternatives to face-to-face professional development to promote teacher growth in the wake of new laws and regulations. For example, under the Every Student Succeeds Act (ESSA) in the United States, teachers are asked to implement a schoolwide system of supports that target a variety of outcomes, but most significantly, the improvement of student academic performance and behavior. Under ESSA, these schoolwide initiatives, known as multi-tiered systems of supports (MTSS), work to 
provide robust scholastic and behavioral supports for all learners. These whole school supports offer a three-tiered continuum of interventions for students and can consequently lead to the uniform systematization of school interventions to enhance the outcomes of all learners (ESSA, 2015; Horner et al, 2019; Horner, Sugai, \& Fixsen, 2017; Lane, Menzies, Ennis, \& Bezdek, 2013; Nagro, Hooks, \& Fraser, 2019). To support teachers and enable them to meet the demands of ESSA, professional development must be offered in a way that will enhance educators' skills, while remaining cost-effective and accessible.

Currently, MTSS coaches and leaders of school improvement initiatives possess limited time and resources for supporting staff directly and on a regular basis. Since stakeholders (staff, coaches, administrators, etc.) have limited resources, it is valuable to look towards alternative means for coaching the growth of educator practice. The current professional development opportunities for classroom teachers are time consuming, typically face-to-face, possess minimal relevance to the classroom environment, and present teachers with limited autonomy and choice. In this paper, the authors look towards a new strategy for developing resources for MTSS coaches to support teacher development in the hopes of improving student success within the PreK-12 setting (Nagro, Hooks, \& Fraser, 2019). These coaches need efficient and effective resources to support teachers, which subsequently improves schools.

To identify the needs of their end users in a more effective way, developers in corporate settings have turned to market development strategy known as Blue Ocean Shift (Kim \& Mauborgne, 2005; 2017). Blue Ocean Shift is an evidenced-based strategy from business that can help schools implement evidence-based practices in the area of PreK-12 professional development. Blue Oceans, as opposed to Red Oceans that are filled with competition, are markets that are untapped by designers. The authors regard the Blue Ocean Shift strategy as an assessment process which, when considered, aids the identification and development of online teaching tools that regional, university, and/or district level MTSS coaches can use to support teachers in their school improvement efforts. The authors examine the current professional development opportunities offered to teachers and evaluate the use of Blue Ocean Shift to distinguish innovative practices that can present MTSS coaches with the tools they need to foster teacher development and student learning.

\section{$2 \quad$ Available Professional Development Opportunities}

\subsection{Face-to-face methodology}

Professional development provided to classroom teachers are typically presented in a face-to-face format, although this method is not the most effective. The one-sizefits-all approach typical to this format is problematic as, "teachers are not a homogenous population but represent diverse perspectives, experience, expertise, receptiveness to new ideas, and potential for leadership roles" (Taylor, Yates, Meyer, \& Kinsella, 2010, p. 85). Since face-to-face professional development, typically provided by school districts for the whole staff, commonly provides non-differentiated content to 
practitioners, it does not always align with the diverse levels of expertise and experience of classroom teachers (Taylor et al., 2010). Additionally, since these meetings generally involve a single day of in-service training, there is limited expectation that teachers will implement these practices within their instruction (Badri, Alnuaimi, Mohaidat, Yang, \& Rashedi, 2016). While professional development is integral to progressing the instructional competencies of teachers, the inability of traditional face-to-face development to meet the needs of all educators is problematic. Many teachers find that face-to-face district-provided professional development does not adequately support their needs (OECD, 2009).

\subsection{Teachers and the learning environment}

Currently, most teachers do not believe that the professional development they are provided by their district meets their needs as there is a disconnect between the content presented to teachers in these meetings and the actual needs of the classroom environment (OECD, 2009). The diverse experiences of teachers cause traditional face-to-face meetings to be incapable of supporting all educators. Likewise, "effective professional development is on-going, includes training, practice and feedback, and provides adequate time and follow-up support. Successful programs involve teachers in learning activities that are like ones they use with their students and encourage the development of teachers' learning communities" (OECD, 2009, p. 49). Since these meetings tend to be one-off instances, teacher growth in relation to their new knowledge is stifled because they are unable to engage in long-term learning that is applicable to the classroom environment. Working to develop a high-quality teacher workforce requires more time than is typically allotted in face-to-face professional development sessions. It is important to look towards alternative, or augmentative, professional development methods that can outperform the face-to-face approach alone.

\subsection{Cost and accessibility}

The common practices used in teacher professional development are, oftentimes, costly and time prohibitive, causing teacher access to be varied. One central reason why teachers are unable to engage in these opportunities (outside of those provided by their district) is due to their time-consuming nature. Classroom teachers currently struggle to balance their immersed work schedule, personal life, and extensive teaching obligations, making it challenging for them to regularly engage in long-term, effective professional development (OECD, 2009). Likewise, both in-person and online opportunities that are not provided by a school district require a substantial amount of money to participate. Such options are expensive to design for classroom teachers because high-quality development opportunities are created by educational experts who are knowledgeable of the best practices that will enrich teacher effectiveness (de Kramer, Masters, O’Dwyer, Dash, \& Russell, 2012). Although face-to-face and online teacher professional development are both costly to design and deliver, face-to-face meetings incur more expenses than online opportunities. Expenditures for 
face-to-face instruction include: travel expenses, presentation fees for facilitators, session design, physical space rental, and participation fees. In addition to these expenses, there may also be a loss of instructional time for teachers because face-to-face learning typically occurs during the school day (de Kramer, et al., 2012). Due to surging expenditures for face-to-face instruction, online professional development presents a cost-effective learning opportunity for teachers to look towards.

A central benefit of online professional development is that an expert facilitator can support participants in a timely manner and interact with them more frequently. Through online professional development, the facilitator is better able to gauge teacher understanding of the material as well as provide individualized support. For example, by examining participants' written reflections on the professional development content, facilitators can evaluate the teachers' content comprehension. Facilitators are then able to offer detailed feedback and supplementary support according to the needs of each classroom teacher (Cho \& Rathbun, 2013). The customized nature of online learning also includes long-term assignments directly tied to the classroom. By extending the length of a professional development session, teachers can, "create work products that would be used in their teaching and which would also provide the [facilitator] with tangible evidence of the effectiveness of what was learned" as well as the value of the professional development (Cho \& Rathbun, 2013, p. 155). Through online learning, educators can engage in professional development that is worthwhile for teachers and coaches alike.

\section{Conducting Valuable Professional Development}

\subsection{Assisting coaches to support teachers}

MTSS coaches provide valuable support for advancing teacher competencies to meet the learning needs of students within the classroom. An educational coach is an individual who works with educators to support their role as a classroom teacher. They offer support with instruction and advise teachers on how to best support the learners in their classroom. For MTSS coaches to have a significant impact on teacher practice, it is imperative that coaches remain respectful and evaluative towards classroom teachers. To engage educators, coaches must implement practices that value teacher autonomy within their classroom. By developing a respectful rapport, a partnership can be formed that fosters open dialogue and enriched teacher practice (Hanover Research, 2015). Ultimately, however, effective coaching must be correlated with teacher and student outcomes. Through continuous evaluation, teacher strengths can be highlighted, areas for improvement can be recognized, and coaches can communicate progress to stakeholders (Hanover Research, 2015). By documenting these elements, while centering the work of coaches on student and teacher outcomes, the classroom environment will improve because growth is grounded in comprehensive learning. One valuable resource for coaches to facilitate professional development is online-based instruction. Implementers of online learning must also consider nuances of working with adults. 


\subsection{Executing adult learning}

Within the academic setting of a professional development session, teachers take on the role of adult learners while coaches become the educator hoping to impart knowledge on teachers in attendance. For the most efficient practices in teaching adult learners, coaches must ensure that teachers are able to freely "work at their own speed, choose to study particular aspects of a course, adopt whatever learning style suits them best, and be free to choose what they learn" (Jarvis, 2004, p. 154). As adult learners, classroom teachers possess the capacity to make decisions about what will best support their professional growth. By constructing a learning environment in which teachers are empowered as independent learners, educators will be more engaged in learning because their insights and experiences are respected.

Online professional development programs must consider practices which properly cultivate the professional growth of educators to subsequently enhance student learning. According to Bichelmeyer (2006), the central features of quality instruction for adults possess the following characteristics:

Encourage student-instructor interaction so that students may become cognitively engaged with the learning environment; Cooperation among students in order to take advantage of the different skills and expertise of the various learners; Encourages active learning so that adult learners are engaged in solving problems and addressing issues that apply to their daily lives; Emphasizes time on task so that the majority of the adult learner's time is spent engaged in learning activities rather than listening to information presented by others; Provides prompt feedback to adult learners about their performance related to learning activities; Communicates high expectations; Involves respecting the diverse talents of adult learners and the various ways in which they learn. (p. 515-516)

Engaging in these practices ensures that classroom teachers, as adult learners, feel their professional development opportunities are advantageous while also providing them chances to apply what they have learned to their personal classroom environment. By guaranteeing content that is applicable to contemporary classrooms, while assessing the previous and present experiences of educators, teachers have a greater ability to engage the material and collaborate with others during the learning process. A teacher's knowledge and mastery of the content will continue to broaden when they are provided with the opportunity to collaborate alongside colleagues and MTSS coaches. When implemented correctly, there are advantages to providing online professional development.

\section{Technology-Based Professional Development Alternatives}

\subsection{Advantages}

Although not the same level as an advanced university-based degree, engaging in online teacher professional development offers opportunities for educators to partici- 
pate in a community for an extended period. One of the benefits of online sessions, as opposed to the one-off, district-provided, face-to-face meeting, is that educator learning opportunities can become long-term and cumulative by allowing teachers to develop and synthesize their skills over time (Gaible \& Burns, 2005; DarlingHammond, Hyler, Gardner, \& Espinoza, 2017). When educators participate in online professional development, they are typically required to generate classroom artifacts related to their work (i.e., teaching strategies, curriculum units, lesson plans, learning goals and objectives). Professional development that is teacher-centered, "values each teacher's needs by supporting each one's active engagement in the [program] and creating knowledge that can be immediately usable in each participant's teaching context (Cho \& Rathbun, 2013, p. 144-145). In a teacher-centered practice, educators can effectively implement educational theory into their classroom setting and reflect on the outcomes over an extended period. Broadening a teacher's learning within the classroom context holds the potential to enrich their effectiveness, thus enhancing student learning.

Another benefit of technology-based professional development is its typically asynchronous nature. In a network meta-analysis, Wu (2019) found that among the three formats commonly used in adult learning - face-to-face, blended, and onlineblended learning appears to be the most efficient form of instruction (P-score= 9946), followed by online $(\mathrm{P}$-score $=.4315)$, and lastly, face-to-face $(\mathrm{P}$-score $=.0793)$. Online learning (blended or fully online) appears to potentially provide better outcomes for adult learners when compared to face-to-face learning opportunities (Wu, 2019). Long-term professional development programs commonly follow a self-paced instructional model or a learning-community model (de Kramer, et al., 2012). Under a selfpaced instructional model, educators independently engage in learning after which they share their knowledge individually to the online facilitator. Conversely, in a learning-community model, educators interact and collaborate with other teachers as well as the online facilitator. Under both models, teachers train online and engage in classroom-centered activities to evolve and develop their practice. Teachers participate in asynchronous communication with the facilitator and/or their fellow teacher participants. The supplemental time provided in this setting offers teachers the opportunity to participate in deeper reflection through the "removal of social and physical boundaries from the communication space" (de Kramer, et al., 2012, p. 239). The asynchronous format of online discussion provides an equal opportunity to share views about the course topics as well as openly discuss learning in relation to the classroom. Both facets are beneficial to the development of reflective practitioners. A flexible schedule is also imperative for educators participating in online learning as they may not always have the means to partake in learning at a specified time or location (Watson, 2008). Ultimately, this structured approach enriches the quality of educator performance as they can focus on professional development at times when they are able to give their absolute attention to the content. 


\subsection{Limitations to online professional development}

Online teacher professional development possesses the capacity to reach educators in new ways and broadens teacher access to quality sessions. One of the drawbacks of offering online-based professional development sessions, however, is that current technologies have the tendency to isolate users. While an online forum can bring educators together, like the self-paced instructional and the learning-community models, it also has the capacity to seclude teachers because the forum does not always require participants to engage in collaborative conversations with other educators (Kebritchi, Lipschuetz, \& Santiague, 2017; National Research Council, 2007). The individualized nature of learning via an online platform has the potential of fostering feelings of isolation because the teacher is working independently in an asynchronous setting. The asynchronous setting of a self-paced instructional model can potentially effect teachers negatively because their independent engagement with the material removes the opportunity to develop their comprehension in relation to the perspectives of their peers. Removing this crucial social component of learning is problematic because it removes a teacher's ability to clarify and refine his/her understandings.

The monetary cost of online teacher professional development is an additional barrier. Because online opportunities are typically provided by knowledge experts, participation in these programs are costly. Unfortunately, the reality is that not all teachers have financial support from their district or the personal finances to participate independently (National Research Council, 2007). Without access to financial support, teachers may be more likely to only engage in the free face-to-face professional development meetings typically provided by the school district. Compounding the cost of these programs, another monetary barrier is the lack of access to personal technology. Many educators do not have access to computers or iPads that allow them to engage in innovative online professional development and collaborate with others (National Research Council, 2007). The lack of financial assistance hinders educators from not only accessing these programs but from affording the technology necessary to participate in the first place. These barriers significantly force teachers into a position where they are less likely to engage in alternative professional development which are technology-based. As it has been established, current face-to-face professional development meetings are unable to account for the diverse needs of teachers and are therefore ineffective. Developers of professional development for educators could use the Blue Ocean Shift approach to address these complications and hindrances to developing training around MTSS.

\section{The Blue Ocean Shift Strategy}

Rather than creating resources that are in competition with existing tools, alternative resources should be developed to meet the unmet needs of schools and educators. Kim and Mauborgne suggest $(2005 ; 2017)$ that many developers create products by comparing their offerings with existing ones in their field. This type of focus is considered a "red ocean." When designers of online content are working within a red ocean, they are looking for ways to develop products that are in some way better than 
other comparable tools. In this case, the developer's goal is to take some additional share of an existing user market like professional development. In contrast, a "blue ocean shift" involves looking for new opportunities to address unsolved problems. Kim and Mauborgne (2005), suggest obtaining first-hand experience of the end user's problem; that is, the issues that teachers directly face with professional development opportunities. In this way, new demands for projects can be captured and created. An example of this strategy is the introduction of Apple's iPod which solved a problem for users trying to carry their music with them more comfortably. The strategy of the blue ocean shift also differentiates a project by lowering the cost to the user, while simultaneously increasing the value an organization can provide them.

When it comes to research and development, the Blue Ocean Shift (BOS) has several advantages over traditional strategic planning. These advantages include:

- Recognizing previously unidentified topics for research from the perspective of multiple stakeholders

- Creating collaborative research experiences

- Generating and capturing a new demand for research and development

- Moving past cost-benefit analysis to focusing on creating value for end users

- Aligning research activities in order to become more efficient, effective and have an increased impact on the end user (Liu, 2008).

The BOS is an improvement over the traditional strategic product develop frameworks because it moves beyond finding ways to compete with existing products and markets.

The BOS approach uses five steps to guide the planning process. Respectively, this five-step approach is formatted in the following order:

- Identify where an organization has the most to gain

- Identify where research teams are now in terms of the innovation

- Imagine the direction of the project as a group

- Identify a path for reaching this goal

- Use processes to select and implement these ideas effectively

Each step utilizes specific procedures that can increase the likelihood of an organization's success. The BOS process will bridge the gap between what is being offered to teachers (face-to-face, online, and university-based graduate education) and their current needs. Figure 1 highlights the theory of change within teacher professional development. To make this change, the first column reflects the current red oceans in professional development which, when exposed to the innovations within the second column, transition towards a blue ocean of efficiency. 


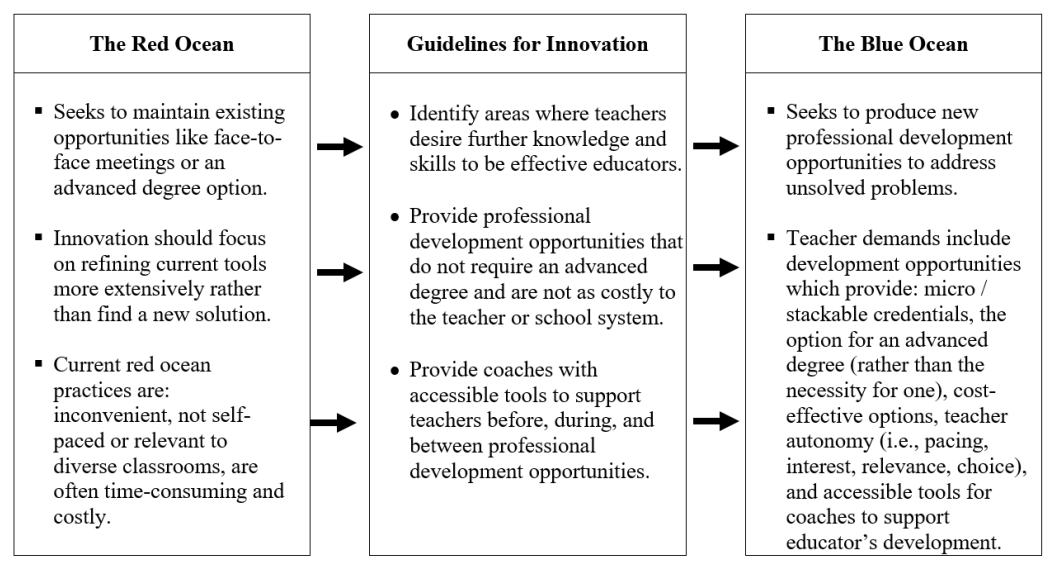

Fig. 1. The blue ocean theory of change in teacher professional development

\subsection{Step One: Identifying where there is the most to gain}

The first step in the BOS process asks a team to identify where they currently are in terms of research and development of a chosen approach. Within the field of education this team is made up of the creators and planners of professional development. The goal here is to establish what research says about the current opportunities being offered to teachers. The BOS further suggests using a visual map to chart this status. It requires an identification, based on the mapped chart, of which area has the most potential for improvement. At the university level, for example, at some institutions there is a perceptible trend in which fewer educators are returning for advanced degrees. Although there are faculty that regularly engage in cutting edge research in their respective fields, educators continue to desire knowledge and skills pertaining to their effectiveness in the classroom. To close this gap, it is essential to identify how educators can be assisted in developing their skills through professional development offerings. For example, a local district may be implementing an MTSS initiative. While they have access to initial professional development and coaching, instructional staff still lack deep skill sets required to implement the approach.

Professional development can be offered in a way that enhances educators' skills with cost-effectiveness in mind. The value of professional development, while not on the same level as an advanced degree, must match the needs of educators in the field to carry out their work. Continuous efforts to meet such needs can only be achieved once the unmet demands in the market are pinpointed and value is allocated to the end users.

\subsection{Step Two: Identifying where the team is in terms of innovation}

To estimate where a team stands in terms of innovation, Kim and Mauborgne (2017) suggest using a technique known as the canvas tool. This tool provides a onepage visual analysis that describes the current opportunities of one district compared 
to what others are offering in the field. For example, within the field of MTSS, the following areas can be advantageously analyzed for this form of comparison:

- How teachers in the local districts are supported in their implementation of MTSS professional development by the district, universities, or other technical assistance providers

- How teachers and MTSS coaches perceive these offerings

- How current offerings (e.g., online, books, webinars) address the needs of teachers and coaches who implement effective strategies for students.

A strategy canvas tool can contrast what is currently being offered to a district with the most valuable resources in the field of professional development. To exemplify this, one might compare one's own university existing courses on MTSS to an organization that provides online modules to teachers in the field (see Association for Supervision and Curriculum Development for examples of online modules). Perspective, according to the BOS, should be from the lens of an end user not the developer. This step will help to divulge how a product competes with others in terms of time and resources for end users. Figure 2 presents a strategy canvas that examines the teacherdetermined value of current professional development opportunities made available to them.

Strategy Canvas: Comparing the Value of Professional Development Opportunities High

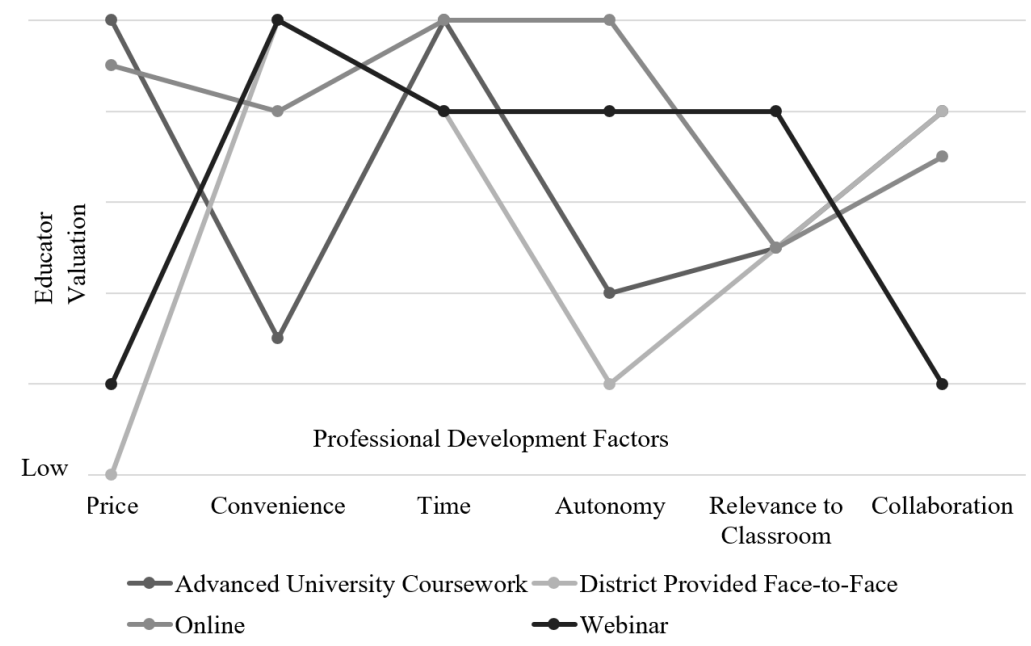

Fig. 2. A stragery canvas which fuctions to analyze current professional development offering according to what teachers value 


\subsection{Step Three: Imagining the project's direction}

The next stage of development involves creating a user utility map (see Figure 3). This map includes the steps that most consumers of any product go through when they commit to using a resource - from selecting a resource to its discard. The vertical axis of the map suggests areas consumers consider at the time of a product's purchase. These factors cover how the product will enhance their productivity, and the resource's simplicity and convenience. The horizontal axis consists of stages consumers go through during a significant purchase. Buyers typically follow a continuum of steps when purchasing a product. Developers can use this map to compare their current and potential offerings for consumers on each quadrant of the matrix.

As the user utility map is developed, the main points of potential users must be identified; in this case, teachers and MTSS coaches. This step further seeks to establish the unmet needs of these potential users and how current professional development opportunities (e.g., the face-to-face format or online modules) can be intimidating to them. To illustrate this universally, take the following example: many people are intimidated by the remote controls that come with new televisions. In fact, some prefer a remote with fewer buttons that guide various functions rather than multiple remotes that each have distinct purposes. The end-user's perspective should be the final guide for determining the functionality of a product.

Focus must remain on the utility of the project across three main groups of people. The first group includes individuals who are soon to be a non-consumer. These could be educators who are utilizing current opportunities but actively looking for another solution. The second group are those that are refusing a product. These are educators who have actively considered utilizing professional development opportunities but have ultimately chosen not to. The third group includes the unexplored nonconsumers. This group comprises educators who have never thought of using alternative resources that a research and development team can provide. For instance, some teachers may be struggling to implement MTSS in their classrooms, but have never thought about accessing online content to support their implementation efforts. Again, the goal is to assess the available opportunities, or potential ones, through the eyes of the end user. In the example provided in Figure 3, the "X" in the matrix indicates an area of focus for one's competitors in one's industry. An "O" in the matrix indicates that one's new Blue Ocean offering will address this area. Some areas of the figure are left blank because neither approach addresses that quadrant. 
Buyer Utility Map: The Six Stages of Buyer Experience Cycle

\begin{tabular}{|l|c|c|c|c|c|c|}
\hline & Purchase & Delivery & Use & Supplements & Maintenance & Disposal \\
\hline $\begin{array}{l}\text { Educator } \\
\text { Productivity }\end{array}$ & $\mathrm{O}$ & $\mathrm{O}$ & $\mathrm{O} / \mathrm{X}$ & $\mathrm{O} / \mathrm{X}$ & $\mathrm{O}$ & \\
\hline Simplicity & $\mathrm{O}$ & $\mathrm{O}$ & $\mathrm{O}$ & $\mathrm{O}$ & $\mathrm{O}$ & $\mathrm{O}$ \\
\hline Convenience & $\mathrm{O}$ & $\mathrm{O}$ & $\mathrm{O}$ & $\mathrm{O}$ & $\mathrm{O}$ & $\mathrm{O}$ \\
\hline Risk & $\mathrm{O}$ & $\mathrm{X}$ & & $\mathrm{O}$ & $\mathrm{O}$ & $\mathrm{O}$ \\
\hline $\begin{array}{l}\text { Fun and } \\
\text { Image }\end{array}$ & $\mathrm{O}$ & $\mathrm{O}$ & $\mathrm{O}$ & & & \\
\hline $\begin{array}{l}\text { Environmental } \\
\text { Friendliness }\end{array}$ & $\mathrm{O}$ & $\mathrm{O}$ & $\mathrm{O}$ & $\mathrm{O}$ & $\mathrm{O}$ & $\mathrm{O}$ \\
\hline
\end{tabular}

$\mathrm{X}=$ Current Industry focus; $\mathrm{O}=$ Blue Ocean Offering

Fig. 3. Example of utility map for crating products for edicators

\subsection{Step Four: Identifying a path to reach the goal}

Step four focuses on how to solve any unmet needs of the end users. The Blue Ocean Shift process suggests using a user utility map that follows six key phases. First, the obstacles which the project is attempting to solve must be identified. As mentioned in the previous step, the end users are not just educators who currently utilize professional development opportunities, but those who may never have considered engaging them in the past. The current obstacles which teachers face in professional development may include support for implementation of strategies and relevance of content to meet the needs of their students. Second, the two largest strategic groups in the field must be established. This phase might consider why teachers and administrators choose to purchase an instructional or pedagogic book rather than hire a consultant for development opportunities. Third, developers distinguish the chain of people who must commit to using the professional development resources financially. This commitment may be comprised of staff time specifically allotted for the use of either free services or those which must be paid for. These individuals might include, but are not limited to: state education agencies, regional offices of education, local education agencies such as school districts, building administrators, department chairs, and school staff. Fourth, determine the consumers' perception of the industry. Specifically, developers should identify overarching themes in changes which are likely to come thereafter (changes in policy, accountability, etc.). This phase seeks to identify trends in the overall field of education, particularly those that seem to be irreversible. For example, if standards-based education begins growing in prominence, then its inclusion in professional development must be considered. Fifth, seeks to identify educational trends based on the online product under development. For each shift, it is crucial to detail how that trend will change what the end users value and how their needs will impact what is being offered to the organization over time. Sixth, ask the team to record their insights from each of the previous actions. The goal of this utility map is to help identify potential actions that will improve opportunities available in professional development by eliminating irrelevant materials, reducing 
efforts to access content, raise the emphasis on key areas, and create new options as needed.

For example, teachers may be implementing an MTSS approach that is designed to increase student engagement within their classrooms. The competing instructional offerings require the teachers to complete a three-credit hour, face-to-face course on instructional strategies. The cost for the course is $\$ 3,000$ in tuition. The Blue Ocean offering may alternatively offer a short (4 hour) online professional development that teachers can complete for continuing education credit at a cost of $\$ 100$. The Blue Ocean offering would only focus on the particular skill-set the teacher is trying to improve (i.e., student engagement). The Blue Ocean offering could include options such as

- Access to an online module and workbook at $\$ 100$ (basic option)

- Access to the modules and workbook, plus membership in a supported social media platform for collaboration with others for \$200 (advanced option)

- All of the aforementioned resources, plus access to three synchronous online small group coaching video sessions for $\$ 400$ (premium option).

In this example, the Blue Ocean offering reduces the cost of the course, the amount of content presented, and the time needed to travel to campus. The offering is increasing the choice teachers have in the level of support they need to implement their MTSS strategy in the classroom.

\subsection{Step Five: Implementing the ideas successfully}

The last strategy of the BOS is to select a final approach to research and develop. To accomplish this step, Kim and Mauborgne (2017) recommend holding a "fair" to share the visual examples of the work teams have created in the previous steps. During this fair, the main intent is to invite leaders from other organizations, the development team, representatives of users from current opportunities, and representatives from non-customer groups in order to present what strategic options have been newly designed. The two primary goals of the fair are to obtain feedback about the current direction of research and development and then share the reasons behind why one idea is chosen over another. The participants are then asked to vote on each possible strategy and share how they made their final decision. The second goal is to secure a commitment from the internal team and stakeholders who collectively agree on the direction in which to head. Because various groups of people have become involved since the beginning of the BOS process, there is a greater likelihood of obtaining commitments for the time and resources necessary to move forward in the approach. Once a particular strategy is determined, end users can then be rapidly tested before rolling out the final product.

It is imperative that the chosen model is financially viable. This includes addressing the cost of resources needed to implement and maintain the work. It is crucial to consider the expense of the product for end users as it can signify its potential sustainability. While developing approaches, using grant funding can be helpful straightaway, this does not always lead to continuation. The expense to the end user reflects 
how much it costs to develop and maintain the product, compounded by the value the offering provides. As previously established, educators are already constrained by the costly nature of professional development. For this reason, it is vital that the opportunities offered to educators within the district are not only affordable for them, but affordable for the administration as well so as not to drain financial resources that are needed elsewhere. One consideration to keep the costs of production down is to partner with existing groups within the organization that can help with implementing the chosen strategy. Specifically, if an organization already has course designers familiar in the development of online training for effective instruction, partnering with them has the potential to yield cost saving resources, not to mention time. Another key strategy in rolling out the project is to empower those who will be interacting with the end users in a way that they feel as if they are a part of the team. The most important people on the team, once the product is ready for implementation, are those who are interacting with the end users. This includes faculty working directly with schools or the enrollment coordinators that interact with potential teacher participants that utilize online resources. Treating these individuals with respect and appreciation goes a long way towards energizing their efforts to be ambassadors for the approach. Although an online training product may seem to be beneficial, if the people interacting with the end users are not as invested in the work, then the project very well may not take off as hoped. Development teams should also consider the investment of MTSS coaches who provide support for the implementation of professional development.

The BOS further suggests drawing a model for how the product will be maintained over time. This model incorporates the project benefits in the organization (e.g., increased revenues in teacher enrollment and enhancements in the use of technology across other more traditional programs) and the advantages for end users (e.g., ability to supplement content from face-to-face training and access to relevant content to support instructional staff). Having a visual model helps everyone on the team understand how to sustain the project. The last component of step five is to initiate implementation with a small pilot. According to Kim and Mauborgne (2017), Apple started with only two physical retail stores. This allowed the company to test their approach and identify any problems that needed to be addressed. After this pilot, they eventually developed 25 new stores, which ultimately lead to 490 stores worldwide. Kim and Mauborgne refer to this as a smart rollout strategy. In the field of education, this might involve testing an approach with one or two schools first. Then, upon success, expand it to the next district followed by the region and then eventually the entire state. A slow and sequential rollout will help the team develop an approach that is more likely to be well received and expand itself effectively over time.

For instance, the Blue Ocean fair might lead to the development of an online professional development to help teachers in a large urban district to improve their classroom climate. As previously mentioned, the suggested offering might include three price points that cover a support continuum. The price points would range from basic access to the materials to MTSS coaching from content experts. The offering would also provide the district's MTSS coaches with access to the social media platform and assessment results. Coaches could tailor their professional development and feedback based on the teachers' progress through the curriculum. Finally, participants could 
have payment plans which allow them to pay for the course over three monthly installments or pay all at once at a discount. Piloting the course before a significant rollout would be critical.

A pilot evaluation project might be implemented with a district and include mechanisms for rapid feedback. For example, staff could be asked to complete a selfassessment on their satisfaction with online content, a pre-post checklist on the level of fidelity of implementation of the strategies within the professional development, and a pre-post measure of classroom climate for their focused setting. District coaches also could provide feedback on their satisfaction with the effectiveness of the content to support the school's MTSS implementation efforts. Alternatively, using a controlwaitlist evaluation design, teachers could be assigned to a treatment (e.g., access to the modules at different levels of support) or control condition (e.g., access only to the district MTSS training and coaching). After an initial evaluation stage, teachers in the control group could have access to the full offering. Ideally, a random selection of the treatment group would be observed to determine their level of implementation of the offering over the duration of the course. Brief interviews or focus groups also could be added at the end of the evaluation period to obtain additional feedback about the value and utility of the offering. These evaluations would provide evidence for the efficacy and efficiency of the Blue Ocean strategy and suggest improvements for scaling the offerings to additional settings.

\section{Conclusion}

Coaches and leaders of MTSS-related school improvement initiatives have limited time and resources to work with staff directly. They require efficient tools to help train and support staff. The BOS process is one way that developers of online tools for coaches and leaders can identify effective resources that benefit everyone involved. Few tools exist that were designed to support individuals who are coaching staff within schools. The BOS process will allow districts to identify the needs and problems of these individuals. If these tools can be provided within MTSS efforts, they may have the ability to improve outcomes for all students, including those who are struggling academically. Creative tools can help the instructional staff to be more successful implementing MTSS. The BOS process provides developers of online professional development with strategies beyond typical research and development. It is possible that this business model can be implemented with a variety of development needs to increase the success of students and teachers in PreK-12 schools. The key ingredients needed to address these demands are a desire to add value to the end user and an effective process such as the BOS to help meet these needs. Optimistically speaking, the value of innovations developed through the BOS will help to identify the needs of end users and those potential users who have never considered using what is being offered. 


\section{$7 \quad$ References}

[1] Badri, M., Alnuaimi, A., \& Mohaidat, J. (2016). Perception of teachers' professional development needs, impacts, and barriers. SAGE Open, 6(3), 1-15. https://doi.org/10.1177/2 158244016662901

[2] Bichelmeyer, B.A. (2006). Best practice in adult education and e-learning: Leverage points for quality and impact of CLE. Valparaiso University Law Review, 40(2), 509-520.

[3] Cho, M. \& Rathbun, G. (2013). Implementing teacher-centred online teacher professional development (oTPD) programme in higher education: A case study. Innovations in Education and Teaching International, 50(2), 144-156. https://doi.org/10.1080/14703297.2012.76 $\underline{0868}$

[4] Darling-Hammond, L., Hyler, M.E., \& Gardner, M. (2017). Effective teacher professional development. Washington, D.C.: Learning Policy Institute.

[5] de Kramer, R.M., Masters, J., O’Dwyer, L.M., Dash, S., \& Russell, M. (2012). Relationship of online teacher professional development to seventh-grade teachers' and students' knowledge and practices in English Language arts. The Teacher Educator, 47(3), 236-259. https://doi.org/10.1080/08878730.2012.685795

[6] ESSA (2015). Every Student Succeeds Act of 2015, 114-95 § 114 Stat. 1177 (2015-2016).

[7] Gaible, E. \& Burns, M. (2005). Models and best practices in teacher professional development. In Using technology to train teachers (pp. 15-26). Washington, D.C.: The International Bank for Reconstruction and Development/The World Bank.

[8] Hanover Research (2015). Best practices in instructional coaching. Arlington, VA: Hanover Research.

[9] Horner, R. H., Sugai, G., \& Fixsen, D. L. (2017). Implementing effective educational practices at scales of social importance. Clinical Child and Family Psychology Review, 20(1), 25-35. https://doi.org/10.1007/s10567-017-0224-7

[10] Horner, R. H., Ward, C. S., Fixsen, D. L., Sugai, G., McIntosh, K., Putnam, R., \& Little, H. D. (2019). Resource leveraging to achieve large-scale implementation of effective educational practices. Journal of Positive Behavior Interventions, 21(2), 67-76. https://doi.org/ $10.1177 / 1098300718783754$

[11] Jarvis, P. (2004). Adult education and lifelong learning: Theory and practice, 3rd ed. London: Falmer Press. Retrieved from: http://site.ebrary.com/lib/oculryerson/docDetail.action? docID $=10093530 \& p 00$

[12] Kebritchi, M., Lipschuetz, A., \& Santiague, L. (2017). Issues and challenges for teaching successful online courses in higher education: A literature review. Journal of Educational Technology Systems, 46(1), 4-29. https://doi.org/10.1177/0047239516661713

[13] Kim, W. C., \& Mauborgne, R. (2017). Blue ocean shift: Beyond competing. New York, NY: Hachette Books.

[14] Kim, W. C., \& Mauborgne, R. (2005). Blue ocean strategy: from theory to practice. California Management Review, 47(3), 105-121. https://doi.org/10.2307/41166308

[15] Kurshan, B. (2015, November 19). The teacher as the learner: Professional development for online and blended learning. Forbes, Retrieved from https://www.forbes.com/\#4f06752 $\underline{\mathrm{e} 2254}$

[16] Liu, G. Z. (2008). Innovating research topics in learning technology: Where are the new blue oceans? British Journal of Educational Technology, 39(4), 738-747. https://doi.org/ 10.1111/j.1467-8535.2008.00851.x

[17] Nagro, S. A., Hooks, S. D., \& Fraser, D. W. (2019). Over a decade of practice: Are educators correctly using tertiary interventions? Preventing School Failure: Alternative Educa- 
tion for Children and Youth, 63(1), 52-61. https://doi.org/10.1080/1045988x.2018.149102 1

[18] National Research Council (2007). Enhancing professional development for teachers: potential uses of information technology: Report of a workshop. Washington, D.C.: The National Academies Press.

[19] OECD (2009). The professional development of teachers. In Creating Effective Teaching and Learning Environments: First Results from TALIS (pp. 47-79). https://doi.org/10.17 $\underline{87 / 9789264068780-5 \text {-en }}$

[20] Schwartz, M. (2014). Engaging adult learners. Ryerson University: Learning \& Teaching.

[21] Taylor, M., Yates, A., Meyer, L.H., \& Kinsella, P. (2010). Teacher professional leadership in support of teacher professional development. Teaching and Teacher Education, 27, 8594. https://doi.org/10.1016/j.tate.2010.07.005

[22] Watson, J. (2008). Promising practices in online learning: Blending learning: The convergence of online and face-to-face education. North American Council for Online Learning.

[23] Wu, M. (2019). Examining the electronic survey response rate in educational research and effectiveness of online learning. Lecture at Loyola University of Chicago School of Education Faculty Research Series.

\section{Authors}

Jenna Nelson is an Assistant Professor of Curriculum and Instruction in the College of Graduate Studies at Concordia University Chicago.

Hank Bohanon is a Professor in Teaching and Learning in the School of Education at Loyola University of Chicago.

Article submitted 2019-04-18. Resubmitted 2019-07-08. Final acceptance 2019-07-20. Final version published as submitted by the authors. 